\title{
Análise crítica do modelo BPSO-96 de QVT a partir da teoria da atividade de $A$. N. Leontiev
}

\section{Critical analysis of the BPSO-96 model of QWL based on A. N. Leontiev's theory of activity}

\author{
Flavia Pracidelli ${ }^{1}$, João Henrique Rossler ${ }^{2}$
}

\begin{abstract}
Resumo
Este artigo, fruto de uma dissertação de mestrado cuja metodologia adotada foi a pesquisa teóricobibliográfica, discute criticamente o que se convencionou denominar como Qualidade de Vida no Trabalho (QVT), a partir da teoria da atividade de A. N. Leontiev, tendo como objeto específico de análise o modelo Biopsicossocial e Organizacional (BPSO-96) de QVT. Para isso, revisa o conceito e a história da QVT, bem como apresenta uma síntese das críticas a ela já apontadas por diversos autores. $\mathrm{Na}$ sequência, define e analisa o modelo BPSO-96. O intuito é contribuir com os estudos críticos da QVT, demonstrando que se trata de uma estratégia de gestão cujo objetivo velado é o aumento da produtividade do trabalhador, por meio de métodos que manipulam objetiva e subjetivamente os motivos da atividade de trabalho e obscurecem em sua consciência seu sentido alienado. Dessa forma, este artigo visa contribuir para o processo de tomada de consciência dos reais objetivos e consequências dos programas de QVT para a classe trabalhadora, mostrando que, apesar de seu discurso pseudohumanista, esta estratégia de gestão atende prioritariamente aos interesses de maior produtividade da organização.
\end{abstract}

Palavras-chave: Qualidade de vida no trabalho. Modelo BPSO-96. Teoria da atividade.

\begin{abstract}
This paper, a product of master's dissertation whose methodology adopted was a theoretical-bibliographic research, discusses critically what has been agreed to be called as Quality of Working Life (QWL), from the A. N. Leontiev's theory of activity. The specific object of analysis is the Byopsychosocial and Organizational model (BPSO-96). Thus, the study revises the concept and the history of QWL as well as presents a summary of the criticisms already pointed out by several authors. Then, it defines and analyzes the BPSO-96 model. The intention is to contribute with the critical studies of QWL, demonstrating how this is a management strategy whose hidden aim is to increase worker productivity through methods that objectively and subjectively manipulates work activity's motives and obscure the alienated sense in workers consciousness. Thus, this paper aims to contribute to increase awareness of the actual objectives and consequences of the QWL to the working class, revealing that despite the pseudo-humanistic speech, this managing strategy serves mainly to increase the organization's productivity.
\end{abstract}

Keywords: Quality of working life. BPSO-96 model. Theory of activity.

\footnotetext{
1 Mestre em Psicologia pela Universidade Federal do Paraná - UFPR. E-mail: flaviapracidelli@hotmail.com

2 Doutor em Educação Escolar pela Universidade Estadual Paulista Júlio de Mesquita Filho (UNESP), e Professor Associado do Departamento de Psicologia da Universidade Federal do Paraná - UFPR. E-mail: jhrossler@ufpr.br / joheross@yahoo.com.br
} 


\section{Introdução}

Este artigo resulta de uma dissertação de mestrado, financiada pela CAPES, que tem como objetivo analisar criticamente, a partir da teoria da atividade de A. N. Leontiev, o que se convencionou chamar, no campo da gestão organizacional, de Qualidade de Vida no Trabalho (QVT). Para tanto, utiliza-se da pesquisa teórico-bibliográfica enquanto metodologia, e toma como objeto de análise específico o modelo Biopsicossocial e Organizacional (BPSO-96) de QVT.

A teoria da atividade surgiu no campo da psicologia a partir dos estudos do psicólogo russo Leontiev $^{3}$ (1904-1979), que juntamente com L. S. Vigotski (1896-1934) e A. Luria (1902-1977) fundaram a Psicologia Histórico-Cultural, com base na filosofia marxista. Já o modelo BPSO-96, desenvolvido a partir da tese de doutorado da autora Limongi-França (1996), representa um conjunto de indicadores para analisar a qualidade de vida no trabalho no interior das organizações. Ao mesmo tempo, esse modelo contribui para o estabelecimento de parâmetros para se pensar e implementar ações e programas de QVT nas organizações brasileiras.

A relevância do referido modelo no campo dos estudos sobre a QVT se dá em razão da sua grande repercussão acadêmico-científica. Limongi-França é uma das autoras mais citadas nacionalmente no assunto. $\mathrm{O}$ conjunto de suas obras referentes à QVT foi citado por 1.496 trabalhos acadêmicos, e sua tese de doutorado, em que apresenta o modelo BPSO-96, foi cotada em 134 citações acadêmicas até março de 2017, conforme dados do Google Scholar.

O número significativo de citações encontradas indica que as obras da autora sobre QVT são amplamente difundidas em trabalhos científicoacadêmicos, o que nos permite concluir que o modelo BPSO-96 exerce forte influência na forma de se pensar e avaliar o tema da QVT na academia brasileira. Isso justifica, portanto, a importância de estudos teóricos que analisem criticamente o referido modelo, em especial considerando seu potencial de aplicação, ou seja, os seus desdobramentos práticos para os trabalhadores, que são afetados diretamente pela implementação dos modelos de gestão desenvolvidos na academia e revestidos de um caráter científico.

O presente artigo está estruturado de forma que, num primeiro momento, há a contextualização teórica do objeto de pesquisa por meio de uma recapitulação histórica e revisão conceitual da QVT a partir do olhar de autores que abordam essa temática de maneira hegemônica, enquanto um recurso e uma estratégia de gestão que busca atender prioritariamente aos interesses das organizações. Posteriormente, há um levantamento do estado da arte da crítica à QVT a partir de autores que buscam denunciar os reais objetivos e consequências desses programas para a classe trabalhadora. $\mathrm{O}$ terceiro item apresenta e descreve o objeto de estudo específico deste artigo, o Modelo Biopsicossocial e Organizacional (BPSO-96) de QVT. O quarto item tem como objetivo a realização da análise crítica a partir da teoria da atividade de A. N. Leontiev, que será abordada e articulada com o objeto específico de pesquisa deste artigo, o modelo BPSO-96. Por fim, o último item retoma alguns autores críticos abordados do decorrer do artigo a fim de realizar as conclusões a respeito de qual seria uma possível solução para a real melhoria da qualidade de vida no trabalho.

\footnotetext{
3 A. N. Leontiev nasceu em Moscou em 1904. Em conjunto com Vigostki e Luria, critica concepções idealistas e mecanicistas biologizantes das aptidões humanas, defendendo uma teoria da natureza sócio-histórica das funções especificamente humanas, as funções psíquicas superiores. Realizou estudos focados na origem e estrutura da atividade humana, pesquisando o seu papel na formação e no desenvolvimento do psiquismo. Suas ideias são retratadas em suas principais obras, "O Desenvolvimento do Psiquismo" e "Atividade, Consciência e Personalidade."
} 


\section{A Qualidade de Vida no Trabalho}

A preocupação com o problema da qualidade de vida no trabalho existe desde o início da humanidade. No entanto, foi apenas nos séculos XVIII e XIX que as inquietações relativas às condições de trabalho e seu impacto sobre a produção e sobre o trabalhador vieram a ser estudadas de forma científica. Essas investigações, oriundas da Administração Científica, dos movimentos da Escola de Relações Humanas e da abordagem Sociotécnica, no campo da Administração, tinham como objeto o bem-estar do trabalhador, sua adaptação à tarefa e a melhora de desempenho e produtividade, o que impulsionou os estudos sobre o assunto (RODRIGUES, 2008).

A denominação Qualidade de Vida no Trabalho (QVT) surgiu nos anos 1950, a partir do estudo de Eric Trist e colaboradores, no Tavistock Institute of Human Relations, na Inglaterra, sobre um modelo que visava inter-relacionar o trinômio indivíduo/ trabalho/organização (FERNANDES, 1996; RODRIGUES, 2008). Contudo, foi apenas na década de 1960 que esses estudos efetivamente tomaram impulso, dada a conscientização da importância de se buscar melhores maneiras de organizar o trabalho, a fim de minimizar os efeitos deletérios da atividade produtiva sobre o trabalhador e aumentar seu bem-estar geral (RODRIGUES; 2008; TOLFO; PICCININI, 2001).

Por trás desses objetivos, no entanto, havia o fato de a competitividade do mercado exigir novas formas de incremento da produtividade do trabalhador. Nesse contexto, a QVT passou a ser considerada, para as organizações, um aspecto tão importante quanto as inovações tecnológicas, em termos de produtividade (LIMONGI-FRANÇA; ARELLANO, 2002). Assim, conforme Ferreira, Alves e Tostes (2009), na década de 1970 a QVT passou a ser objeto de grande investimento financeiro, especialmente nas grandes corporações.

De acordo com Rodrigues (2008), foi nessa época que surgiram as primeiras sistematizações e aplicações estruturadas de QVT no interior das empresas, impulsionadas pelo contexto de mudança de enfoque no gerenciamento organizacional a qual foi influenciada pela crise do modelo de acumulação taylorista-fordista e pelo sucesso do modelo japonês toyotista. Esse é o caso, segundo Chiavenato (2010), de Louis Davis, nos Estados Unidos, que emprega o termo QVT ao desenvolver um projeto de desenho de cargos, relacionando o conceito à preocupação com o bem-estar e a saúde dos trabalhadores (ora denominados colaboradores) no desempenho de suas tarefas.

Segundo Nadler e Lawler (1983 apud LIMONGIFRANÇA; ARELLANO, 2002), a partir de 1979 o movimento da QVT ganhou ainda mais repercussão no meio gerencial, estimulado pela competição internacional. Algumas iniciativas, como as da General Motors, começaram a ganhar popularidade, visto seu reflexo na produtividade organizacional. Com isso, um grande número de projetos americanos de QVT foi implantado, de modo que o auge do modelo foi atingido nos anos de 1980.

A década de 1990 foi marcada pelo grande desenvolvimento da QVT no âmbito acadêmico, e também pela sua popularização no mundo corporativo em diversos outros países - como Inglaterra, Canadá, México e Brasil - por meio da literatura administrativa sobre o comportamento organizacional e os programas de qualidade total (BOM SUCESSO, 1998; CAMPANA, 2011). Segundo Fernandes (1996), no Brasil, em especial, o interesse pela QVT surgiu nessa década, a partir da abertura para a importação de produtos estrangeiros e diante da implementação dos programas de qualidade total, considerando-se sua relação com a produtividade e a competitividade no mercado.

Conforme Limongi-França (2003), a ascensão da QVT, no decorrer da década de 90, deu-se de forma gradativa e sistemática: de características essencialmente operacionais ligadas às questões de saúde e segurança para ações corporativas estratégicas referentes à qualidade pessoal, 
às qualificações profissional e cultural, ao planejamento, ao trabalho voluntário e à cidadania. Assim, as práticas e os conceitos de QVT evoluíram de uma perspectiva predominantemente voltada para a saúde e a segurança para um status de estratégia empresarial. Isso porque, segundo a autora, a QVT oferece uma importante contribuição no desafio de alinhar a valorização da condição e do pleno desenvolvimento humano ao posicionamento estratégico empresarial.

A despeito de sua história e de sua consolidação como estratégia fundamental da gestão empresarial, a definição da QVT permaneceu difusa em termos conceituais, embora alinhada quanto ao seu objetivo central, qual seja o incremento da produtividade do trabalhador. Segundo Limongi-França e Arellano (2002), a QVT se constitui hoje como um processo que consolida a busca pelo desenvolvimento humano e organizacional. $\mathrm{O}$ conceito envolve uma compreensão abrangente e comprometida com as condições de vida no trabalho, de forma a garantir o bem-estar, a saúde e a segurança física, mental e social, além da capacitação para realizar tarefas com segurança e bom uso da energia pessoal (LIMONGI-FRANÇA; RODRIGUES, 1996).

Já para Fernandes (1996, p. 45), o conceito de QVT envolve "a gestão dinâmica e contingencial de fatores físicos, tecnológicos e sóciopsicológicos que afetam a cultura e renovam o clima organizacional, refletindo-se no bem-estar do trabalhador e na produtividade das empresas". Para Rodrigues (2008), por sua vez, o termo é entendido pela combinação direta de diversas dimensões básicas da tarefa e de vários outros fatores não dependentes dela. Esta combinação é capaz de produzir motivação e satisfação em diferentes níveis, resultando em possibilidades variadas de comportamentos individuais e coletivos.

Conforme Limongi-França e Arellano (2002), para Walton a QVT é o conjunto de valores ambientais e humanos negligenciados pelas sociedades industriais na busca pelo crescimento econômico e tecnológico. Em obra publicada em 1975, este autor explica que a QVT surge com objetivos atrelados à legislação trabalhista, como a regulamentação da jornada de trabalho e do descanso semanal, e as indenizações por acidentes de trabalho.

Contudo, o modelo vai além desses objetivos iniciais. Tolfo e Piccinini (2001) esclarecem que, para Walton, a QVT deve estar relacionada à humanização do trabalho e à responsabilidade social da empresa. Para isso, parte da compreensão das necessidades e aspirações individuais para o desenvolvimento de novas formas de organizar o trabalho. Segundo Ferreira, Alves e Tostes (2009), Walton defende que a QVT depende do equilíbrio entre trabalho e as outras esferas da vida, e ressalta a importância de se conciliar produtividade com QVT.

Assim, é possível perceber que a definição de QVT é bastante variável, não havendo consenso quanto ao termo (FERNANDES, 1996). Contudo, há algo que parece constante na maioria das abordagens: o esforço em humanizar o trabalho, buscando a melhoria da eficácia organizacional por meio da maior participação dos trabalhadores e de melhores condições de trabalho, a fim de aumentar sua satisfação e incrementar a produtividade da empresa.

\section{O Estado da Arte da crítica à QVT}

A despeito de seu discurso humanizador e conciliador no campo do trabalho, a QVT não esteve ao longo dos últimos anos isenta de críticas contundentes. Se por um lado seu desenvolvimento histórico fundamentou propostas e estratégias para viabilizar o aumento da produtividade do trabalhador por meio da melhoria de sua satisfação e bem-estar no trabalho, por outro lado a crítica aos modelos de QVT denunciam as contradições, os fundamentos e os objetivos velados desses programas, bem como seus efeitos sobre a classe trabalhadora. 
É o caso de Scopinho (2009). Conforme a autora, embora a QVT advenha da ideia de "humanizar" o trabalho, sua origem se encontra em uma preocupação essencialmente gerencial. Para ela, a QVT consiste em um modismo gerencial que busca uma fórmula que contemple as dimensões dos conhecimentos e dos sentimentos dos trabalhadores envolvidos na realização do trabalho, a fim de que estas dimensões sejam controladas pelo gestor na busca pela melhoria da produtividade, qualidade e redução de custos. O conceito de QVT, dessa forma, apresenta forte polissemia, ausência de materialidade e grande relatividade, ao refletir jargões vazios e receitas veiculadas na história da corrida gerencial em busca de maior lucro.

Isso porque, segundo Araújo (2009), a racionalidade da gestão de recursos humanos, que visa essencialmente o aumento da produção e a diminuição de custos, naturaliza as relações de trabalho inerentes ao modo de produção capitalista, atribuindo ao trabalhador o lugar de mero recurso. Para isso, recorre a sucessivas estratégias de manipulação e sedução do trabalho por meio de diversos modismos gerenciais, como é o caso do "humanismo" presente nos programas de QVT.

Todavia, para o autor, o humanismo presente no discurso dos ideólogos do capitalismo é um humanismo contaminado, do ponto de vista teórico, ético e político. Logo, os programas de QVT, como medida de "humanização" do trabalho, estão a serviço do processo de dominação do capital sobre o trabalho, por meio de uma exploração mais civilizada e refinada do trabalhador. Segundo ele, estratégias de gestão como esta objetivam maior controle e a "docilização do fator humano" no sistema de produção, a fim de que este sirva ao capital. Produzem, portanto, um teatro de humanização do trabalho, que seduz o trabalhador e o submete a relações aparentemente amistosas, permitindo uma exploração cada vez mais acentuada (ARAÚJO, 2009).
Com esse teatro de humanização do trabalho, conforme Carvalho e Dourado (2006), as organizações buscam amenizar o conflito existente nas relações de trabalho. Isso porque o conflito essencial entre o capital e os interesses dos indivíduos é encarado como o principal obstáculo ao desempenho do homem no trabalho. Assim, as organizações, que em um primeiro momento atuavam fazendo uso de estratégias de exploração mais visíveis e imediatas, substituíram esse modelo por um sistema de mediações que interioriza as coerções, na tentativa de reduzir os conflitos e conciliar interesses. Portanto, por trás do discurso liberal e dos ajustes nas políticas de tratamento do trabalhador pelas empresas, está a necessidade de transformações no seu controle para minimizar o conflito entre capital e trabalho.

Para os autores, isso explica por que os métodos de controle exercidos pela gestão empresarial ficam cada vez mais sofisticados e com roupagens predominantemente subjetivas, tornando-se mais difíceis de serem desvendados. Para eles, o caráter hegemônico e opressor do sistema é dissimulado por meio de instrumentos de controle e dominação reinventados e sofisticados, cuja natureza transfere o controle social exercido nas empresas para esferas psicológicas e ideológicas. Esse é o caso da QVT: o seu intuito, em última instância, é sempre obter melhorias no desempenho e na produtividade do trabalhador e, consequentemente, maior rendimento organizacional. Nesse cenário, os indivíduos não passam de peças importantes na racionalização dos meios de produção, desempenhando função instrumental nesse processo e estando submetidos à supremacia dos interesses e do poder econômicoempresarial (CARVALHO; DOURADO, 2006).

Scopinho (2009) afirma que a naturalização da precariedade do trabalho, somada à implementação dos programas de QVT, disfarçou a insalubridade, a periculosidade e a penosidade do trabalho, revelando-se como uma forma mais sutil de controle 
sobre os trabalhadores - um controle que tende a ser mais simbólico do que coercitivo e punitivo. Por conta disso, para Carvalho e Dourado (2006), a QVT revela-se como uma das ferramentas mais opressoras e audaciosas de alienação do indivíduo nas organizações modernas, atuando por meio de variados mecanismos de manutenção da condição instrumental do indivíduo no ambiente de trabalho.

Ferreira (2015) explica que os programas de QVT atuam como uma espécie de "remédio" eficaz para gerir as transformações econômicas e seus impactos no campo da saúde e segurança no trabalho. Essas práticas, contudo, caracterizam-se como modos de dominação/submissão dos trabalhadores, de forma que a maximização da produtividade permanece como objetivo central, mas não explicitamente revelado. Além disso, programas como este empobrecem o caráter coletivo do trabalho, colocando a ênfase no indivíduo isoladamente.

Colocando o foco nos indivíduos, tais práticas transferem aos trabalhadores a responsabilidade pela sua qualidade de vida no trabalho, fazendo com que as fontes concretas do desgaste, da fadiga e do estresse, cujas raízes são de natureza organizacional, permaneçam intocadas. Logo, o que os programas de QVT de fato buscam é o aumento da resistência física e mental dos trabalhadores para suportarem às adversidades organizacionais. $\mathrm{O}$ trabalhador, dessa forma, é considerado uma variável de ajuste, devendo se adaptar ao ambiente organizacional hostil (FERREIRA, 2015).

Assim, para Ferreira, Alves e Tostes (2009), as práticas de QVT hegemônicas possuem natureza assistencialista e caráter compensatório e paliativo em relação aos desgastes vivenciados pelos trabalhadores, atuando com uma função essencialmente "curativa", isto é, sanando os males presentes no cotidiano de trabalho. O intuito é que os índices de produtividade organizacional sejam garantidos, baseando-se, portanto, em uma concepção instrumentalista e utilitarista do trabalho humano centrada no produtivismo exacerbado.
Padilha (2009) reforça essa ideia ao explicar que há uma grande distância entre o discurso e a prática de QVT no que se refere à autonomia e à emancipação do trabalhador. Também para esta autora, o benefício desta política de RH está muito mais voltado para a produtividade organizacional do que para o verdadeiro bem-estar do trabalhador. A QVT, na prática, configura-se como um meio quando deveria, de fato, ser um fim. As políticas de QVT — como ginástica laboral, aulas de ioga, salas de descanso, massagens, dança, artesanato, coral etc. - possuem um caráter assistencial, cujo objetivo é a otimização da produtividade organizacional e a melhoria da imagem positiva da empresa (tanto para os funcionários quanto para o público em geral). Na análise da autora, a QVT é, além do mais, meio para maquiar problemas de ordem estrutural (na organização e na sociedade), transferindo o foco para o indivíduo por meio de uma ideologia de "pão e circo" e desviando a atenção da forma como o capital se organiza e se desenvolve para se reproduzir.

Nesta lógica, o conflito, o desequilíbrio e os problemas do trabalho inerentes à ordem capitalista são negados e não há preocupação em conhecer as suas causas, de forma que os males são tratados apenas paliativamente. Assim, as práticas de QVT atuam como válvulas de escape para proporcionar alívio momentâneo, agindo como um analgésico que ameniza os efeitos sem atacar as suas causas. Nesse sentido, as empresas se transformam em centros de bem-estar com espaços artificiais e atraentes, que diluem o lazer e o esporte no meio dos sacrifícios do trabalho (PADILHA, 2009).

Portanto, para Padilha (2009), assim como para Scopinho (2009) e Araújo (2009), as políticas de promoção de QVT atualmente adotadas pelas empresas podem servir como uma medida paliativa, como uma válvula de escape, um remédio que alivia momentaneamente os sintomas provocados pela intensificação do trabalho, mas não atacam as verdadeiras causas estruturais dos problemas enfrentados pelos trabalhadores. 
De acordo com Padilha (2009), a possibilidade de se aplicar a QVT como fim seria pensar em formas de o trabalhador poder dispor do controle de seu processo de trabalho, ou seja, de ser autônomo, criativo e participativo. No entanto, um cenário como este só seria possível em outro modelo de organização do trabalho. Nele, a QVT seria um fim que se realizaria quase naturalmente, não necessitando ser produzida artificialmente. A humanização do e no trabalho não estaria limitada a eventuais medidas paliativas, próprias de uma compreensão funcionalista. Estaria, isso sim, atrelada a uma sociedade livre das promíscuas relações que se estabelecem em função das regras impostas pelo jogo da acumulação privada do trabalho e da riqueza por ele gerada.

Dessa forma, conforme Araújo (2009), a QVT, enquanto estratégia de gestão de pessoas, não pode promover a saúde do trabalhador em seu sentido pleno, uma vez que isso é impossível sem a democratização das relações sociais produtivas. Além disso, essas relações deveriam estar fundadas em um sistema de trocas no qual a dominação e a alienação fossem excluídas.

\section{O Modelo BPSO-96 de QVT}

A fim de contribuir para o avanço da crítica à QVT, nossa proposta é tomar o modelo Biopsicossocial e Organizacional (BPSO-96) de QVT como objeto de análise. A escolha por este modelo se deu graças à sua penetração e influência no entendimento e avaliação da QVT na realidade brasileira, conforme exposto na introdução deste artigo.

O modelo BPSO-96 surgiu como resultado da tese de doutorado de Limongi-França (1996). Nela, a autora propõe um instrumento de avaliação de QVT por meio de um conjunto de indicadores empresariais. O principal objetivo de sua tese, segundo a pesquisadora, foi a investigação das prováveis relações entre os esforços declarados pela empresa para melhorar a qualidade de vida no trabalho e a satisfação dos empregados. Dessa forma, a opção de estudo exploratório da autora foi de natureza correlacional, de maneira a relacionar a opinião pessoal de satisfação dos empregados aos esforços (ações/programas) declarados pela empresa.

Para a elaboração dos indicadores que compõem o modelo BPSO-96, Limongi-França (1996) adota o enfoque biopsicossocial como embasamento teórico. Esse enfoque, oriundo da Medicina Psicossomática e que tem Lipowski como seu precursor, propõe uma visão holística e integrada do ser humano. Nele, toda pessoa é um complexo biopsicossocial, ou seja, tem potencialidades biológicas, psicológicas e sociais que respondem simultaneamente às condições de vida. As manifestações desses três níveis são interdependentes, embora haja diferentes possibilidades de combinações e intensidades individuais. Conforme a autora, essa conceituação, adotada pela Organização Mundial da Saúde (OMS) desde 1986, intenta resgatar uma visão mais ampla do conceito de saúde, de maneira que este não seja associado apenas à ausência de doença, mas também ao completo bem-estar biológico, psicológico e social.

As dimensões da visão biopsicossocial, segundo Limongi-França (1996), estruturam-se da seguinte forma:

- Dimensão biológica: refere-se às características físicas herdadas ou adquiridas no decorrer da vida. Está relacionada aos fatores de saúde.

- Dimensão psicológica: referente aos processos afetivos, emocionais e de raciocínio, conscientes ou inconscientes, que formam a personalidade de cada pessoa e seu modo de perceber e de se posicionar frente às outras pessoas e a circunstâncias externas.

- Dimensão social: revela fatores socioeconômicos, o papel dos grupos e organizações sociais, a cultura, as crenças, o meio ambiente e a localização geográfica. 
A fim de atender às especificidades da cultura e do ambiente organizacional, a autora acrescenta a essas a dimensão organizacional, a qual se refere à imagem corporativa, aos valores e práticas de gestão e aos sistemas de controle, inovação e tecnologia. Essas dimensões, por sua vez, implicam diferentes indicadores empresariais de QVT. Logo, a sigla BPSO-96 remete às dimensões Biológicas, Psicológicas, Sociais e Organizacionais da QVT e seus respectivos conjuntos de indicadores empresariais (LIMONGI-FRANÇA, 2003).
Limongi-França (1996) esclarece ainda que indicadores são ferramentas que permitem clareza de critérios e facilitação no levantamento, na avaliação e na compreensão de resultados. Os indicadores de QVT propostos por ela e que constituem o modelo BPSO-96 têm como base o Índice de Desenvolvimento Humano (IDH), o Índice de Desenvolvimento Social (IDS) e as categorias de Walton. Os critérios de análise do modelo BPSO-96 são apresentados no Quadro 1.

Quadro 1 - Os critérios de análise do modelo BPSO-96

\begin{tabular}{|c|c|c|c|}
\hline \multicolumn{4}{|c|}{ Critérios de Análise do Modelo BPSO-96 } \\
\hline $\begin{array}{l}\text { Área de } \\
\text { investigação } \\
\text { (Dimensão) }\end{array}$ & Descrição & Ações e Programas (Indicadores) & Células Organizacionais \\
\hline Biológica & $\begin{array}{l}\text { Promoção da saúde e da segurança, } \\
\text { controle dos riscos ambientais e } \\
\text { atendimento às necessidades físi- } \\
\text { cas em geral }\end{array}$ & $\begin{array}{l}\text { - Mapa de riscos } \\
\text { - SIPAT } \\
\text { - Refeições } \\
\text { - Serviço Médico - interno e } \\
\quad \text { contratado } \\
\text { - Melhorias ergonômicas } \\
\text { - Treinamentos específicos } \\
\end{array}$ & $\begin{array}{l}\text { - Segurança do Traba- } \\
\text { lho e Medicina Ocu- } \\
\text { pacional } \\
\text { - Ambulatório } \\
\text { - Nutrição } \\
\text { - Relações Industriais e/ } \\
\text { ou Recursos Humanos }\end{array}$ \\
\hline Psicológica & $\begin{array}{l}\text { Promoção da autoestima e do } \\
\text { desenvolvimento de capacidades } \\
\text { pessoais e profissionais }\end{array}$ & $\begin{array}{l}\text { - Processo de seleção e avaliação } \\
\text { do desempenho } \\
\text { - Carreira } \\
\text { - Remuneração } \\
\text { - Programas participativos }\end{array}$ & $\begin{array}{l}\text { - Recrutamento e Sele- } \\
\text { ção } \\
\text { - Treinamento de Pes- } \\
\text { soal } \\
\text { - Cargos e Salários } \\
\text { - Relações Industriais e/ } \\
\text { ou Recursos Humanos }\end{array}$ \\
\hline Social & $\begin{array}{l}\text { Oferta de benefícios sociais obri- } \\
\text { gatórios e espontâneos e criação de } \\
\text { oportunidades de lazer, esporte e } \\
\text { cultura }\end{array}$ & $\begin{array}{l}\text { - Direitos legais } \\
\text { - Atividades associativas e es- } \\
\text { portivas } \\
\text { - Eventos de turismo, lazer e cul- } \\
\text { tura } \\
\text { - Atendimento à família } \\
\end{array}$ & $\begin{array}{l}\text { - Serviço social } \\
\text { - Grêmio Esportivo } \\
\text { - Fundações específicas } \\
\text { - Recursos Humanos }\end{array}$ \\
\hline Organizacional & $\begin{array}{l}\text { Valorização da imagem corpora- } \\
\text { tiva, da estrutura organizacional, } \\
\text { dos produtos e serviços e do re- } \\
\text { lacionamento da empresa com os } \\
\text { empregados }\end{array}$ & $\begin{array}{l}\text { - Endomarketing } \\
\text { - Comitês executivos e de deci- } \\
\text { são } \\
\text { - Comunicação interna } \\
\text { - Imagem externa, responsabili- } \\
\text { dade social e cidadania }\end{array}$ & $\begin{array}{l}\text { - Diretorias executivas } \\
\text { - Marketing } \\
\text { - Recursos Humanos }\end{array}$ \\
\hline
\end{tabular}

Fonte: Limongi-França (1996, p. 245). 
Os indicadores do modelo BPSO-96 compõem um instrumento de avaliação de QVT que, conforme Limongi-França (1996), permite a análise do comportamento organizacional de forma mais abrangente que a tradicional, tornando possível situar as diversificadas ações e programas de QVT nas empresas pesquisadas. Para isso, faz uso de um estudo exploratório de natureza correlacional, de modo a aplicar o questionário do modelo BPSO-96 tanto com os gerentes de RH (ou função equivalente), a fim de investigar as ações/programas de QVT implantados na organização, quanto com os empregados, para averiguar a satisfação destes em relação à QVT. Os resultados desse trabalho visam contribuir para a implementação, dentro de critérios da abordagem biopsicossocial e organizacional, de ações, políticas e programas de QVT nas organizações.

\section{Análise crítica do modelo BPSO-96 a partir da teoria da atividade de $A$. N. Leontiev}

Alexei Nikolaevich Leontiev elaborou a teoria da atividade para explicar que, diferentemente de outros animais, que se identificam com a sua atividade vital, o ser humano faz dela objeto de sua vontade e consciência. Isso gera uma mudança na estrutura de sua atividade, o que tem efeitos diretos na constituição e no desenvolvimento de seu psiquismo.

Para Leontiev, a primeira condição de toda atividade é uma necessidade, isto é, a necessidade de um objeto para sua satisfação. Somente na atividade é que a necessidade "conhece" seu objeto, fazendo com que adquira sua objetividade. À medida que a atividade encontra a sua determinação no objeto, nele se "objetificando", este se torna o motivo da atividade - aquilo que the estimula e the orienta (LEONTIEV, 1978a, 1978b).

De acordo com o autor, os componentes básicos da atividade humana são as ações, isto é, processos que obedecem a um objetivo/propósito parcial consciente, cujo encadeamento resulta no alcance do objetivo final da atividade. Toda ação, segundo ele, possui um aspecto intencional (o que deve ser feito, sua finalidade) e um aspecto operacional (como e por quais meios isso pode ser alcançado), determinado pelas condições objetivas do objeto de sua realização. Os meios pelos quais a ação é realizada são denominados, por sua vez, de operações. (LEONTIEV, 1978a)

Conforme Leontiev (1978b), na cadeia da atividade vital, para que o homem possa realizar sua ação, é necessário que o objeto de sua ação (o seu fim) possua correlação consciente com o gerador da atividade (o seu motivo). Esta ligação, que condiciona a orientação da atividade, supõe que o sujeito tenha a capacidade de refletir psiquicamente, de modo consciente, a relação que existe entre o objeto de uma determinada ação e o motivo da atividade da qual essa ação é parte integrante.

Com isso, para o psicólogo russo, todas as conexões existentes na atividade vital do homem, que ocorrem por meio do processo de trabalho coletivo, são responsáveis pela origem especificamente humana do reflexo psíquico da realidade: a consciência. Por sua vez, o reflexo consciente é caracterizado, psicologicamente, pela presença de uma relação interna específica: a relação entre significação social e sentido subjetivo, o principal componente da estrutura interna da consciência humana.

Conforme Leontiev (1978a), os significados são produzidos pela sociedade, pela atividade históricosocial dos homens, e possuem sua própria história de desenvolvimento junto ao desenvolvimento da linguagem. Logo, os significados funcionam em processos que apresentam uma ligação direta com a atividade objetiva. O significado, contudo, possui outra vida, outro movimento, no qual assume novas qualidades sistêmicas para o indivíduo, desempenhando outra função psicológica no processo de atividade e na consciência dos indivíduos. Em sua segunda via, os significados são individualizados e subjetivados. Esta faceta 
do movimento dos significados no sistema de consciência individual é expressa na parcialidade que eles adquirem, fazendo com que se desenvolva o outro "formador" da consciência - o sentido pessoal.

Leontiev (1978b) explica a relação entre sentido e significado e os componentes da atividade vital, ou seja, da atividade consciente humana. Para que ela seja realizada, é necessário que aquele que a executa capte em sua consciência a relação entre o objeto da ação (o conteúdo concreto e os resultados imediatos da ação), ou seja, o significado da ação, e o motivo da atividade. Esta ligação que orienta a atividade supõe, conforme o autor, que o indivíduo seja capaz de refletir psiquicamente a relação que existe entre o objeto de uma ação (seu significado) e o motivo da atividade, gerando a distinção na consciência, em termos psicológicos, entre significado e sentido. $\mathrm{O}$ sentido, portanto, depende do motivo. E é a partir dessa relação que a ação se torna dotada não apenas de significado, mas de sentido para o sujeito.

De acordo com Duarte (2004), a divisão social do trabalho e a propriedade privada produziram historicamente a dissociação psicológica entre o significado e o sentido, ou seja, afetaram a estrutura da consciência humana desassociando o significado e o sentido da ação. Ainda conforme Duarte (2008), de modo contraditório a separação entre objeto e motivo, entre significado e sentido da ação na atividade do homem, permitiu que este se tornasse consciente do fim não imediato de suas ações, o que historicamente contribuiu para o desenvolvimento humanizador tanto da atividade quanto da consciência dos indivíduos. Ao mesmo tempo, sob determinadas relações sociais, em especial nas sociedades de classes, esta distinção fez com que o significado e sentido das ações se dissociem quase totalmente, alienando-se.

Foi o que ocorreu com a atividade de trabalho. Segundo Duarte (2008), a partir da dissociação entre significado e sentido, a atividade humana tornou-se uma atividade consciente em que as ações não possuem sentido em si mesmas, mas apenas na relação com o motivo da atividade. Essa dissociação agravou-se ao longo da história no trabalho, no interior das sociedades de classes antagônicas, isto é, pautadas em relações de dominação e exploração de uma classe social por outra.

$\mathrm{Na}$ sociedade de classes atual, capitalista, essa dissociação assume sua forma mais intensa. Nela, o sentido do trabalho encontra-se alienado, por estar integralmente apartado, objetiva e subjetivamente, do conteúdo e do produto dessa atividade. A atividade de trabalho na sociedade capitalista é essencialmente movida pela lógica econômica de reprodução do capital, estando o sentido da atividade subordinado a esta lógica. Afinal, o sentido do trabalho, para o trabalhador, é produzido pelas suas condições objetivas de vida, marcadas em nossa sociedade pela necessidade da venda de sua força de trabalho - necessidade essa que encontra sua objetividade, como motivo, no salário que o trabalhador recebe em troca de seu trabalho. Assim, independentemente de onde trabalhe ou da natureza de sua atividade, seu sentido será dado pelo seu salário, pelo valor de troca de seu trabalho (DUARTE, 2002, 2004).

Duarte (2004), com base em Leontiev, afirma que os aspectos afetivo-emocionais do agir humano são mais dependentes do sentido da atividade, de forma que uma mesma ação pode vir acompanhada de diferentes emoções e sentimentos, dependendo de qual seja a atividade que constitui a totalidade que dá sentido a essa ação. Martins (2001) esclarece que as emoções vão adquirindo uma dimensão motivacional, uma vez que passam a sustentar o sentido experimentado, fazendo com que possam tanto organizar quanto desorganizar a atividade. Uma vez que o motivo e o sentido do trabalho no capitalismo são o salário, um sentido alienado, apartado do conteúdo e do resultado do trabalho, da função social daquilo que o trabalhador produz, as emoções e os sentimentos a ele correspondentes podem ser de insatisfação e sofrimento. Isso 
pode acarretar a desorganização da atividade, a desmotivação e o prejuízo no desempenho do trabalhador, comprometendo sua produtividade.

São justamente esses os "sintomas" do trabalho alienado que historicamente o capital tenta combater por meio do emprego de estratégias de gestão cada vez mais sofisticadas no controle objetivo e subjetivo do trabalhador. Entre elas está a QVT, cujo objetivo central, em nosso entendimento, é inserir novos motivos dentro do processo de trabalho a fim de que a produtividade seja otimizada.

Leontiev (1978a) explica que a atividade humana é composta não apenas de motivos geradores de sentido (que, no capitalismo, para o trabalhador, é o salário), mas também de motivos estímulos. Os motivos geradores de sentido são aqueles que, ao induzir a atividade, conferem-lhe sentido pessoal. Ocupam, assim, um lugar de destaque na estrutura afetivo-emocional e motivacional da personalidade, uma vez que a atividade por eles desencadeada se orienta por uma unidade consciente entre motivos (o por que) e os fins (o para que) da atividade.

Já os motivos estímulos, que podem coexistir com os primeiros, exercem uma função psicológica essencialmente sinalizadora, ao cumprir o papel de impulsionar a atividade sem, contudo, gerar sentido. Do ponto de vista psicológico, sua função é produzir vivências emocionais diretas, efêmeras e imediatas, positivas ou negativas; isto é, sinais internos que estimulam positiva ou negativamente a atividade em uma determinada direção (LEONTIEV, 1978a).

Leontiev (1978a) esclarece que a personalidade é constituída a partir do conjunto de atividades do sujeito, de forma que as particularidades destas atividades definirão o modo como será estruturada sua personalidade, sua hierarquia motivacional. As relações existentes na hierarquia de motivos, constituída pela divisão dos motivos conforme sua função de produção de sentido ou simples estimulação da atividade, tornam possíveis compreender a estrutura motivacional da personalidade. Conforme Martins (2001, p. 97), "chamamos de estrutura motivacional da personalidade o conjunto de motivos construídos pelo indivíduo em decorrência das atividades que o põem em relação com o mundo".

De acordo com o psicólogo russo, a unidade na personalidade do indivíduo deve ser formada a partir de relações autênticas e não alienadas, ou seja, relações advindas de atividades motivadas por motivos formadores de sentido, e não apenas por motivos que apenas lhes estimulem. Contudo, segundo Martins (2001), a organização social capitalista tem determinado a primazia de motivos estímulos em detrimento dos motivos geradores de sentido, uma vez que, na maior parte das vezes, o atendimento aos primeiros é uma questão de sobrevivência material.

É por isso que os atuais modelos de gestão se utilizam de estratégias que trazem para dentro das organizações diversos motivos estímulos para impulsionar o trabalho. A gestão organizacional atual promove no trabalho necessidades que, anteriormente, eram satisfeitas fora dele. O intuito é impulsionar o trabalho vinculando-o a necessidades/ motivos relacionados à esfera extratrabalho. Porém, isso é feito por meio de motivos estímulos essencialmente desvinculados do conteúdo do próprio trabalho, os quais atuam apenas como sinalizadores emocionais internos para impulsionar a atividade do trabalhador. Almeja-se com isso, de forma intencional ou não, atuar sobre a esfera afetivo-motivacional do trabalhador, reorganizando a hierarquia de suas necessidades e o tornando dependente do trabalho para sua satisfação. Em outras palavras, trata-se de um processo de cooptação emocional, isto é, cooptação afetivomotivacional do trabalhador.

Esse recurso gerencial se torna especialmente evidente ao analisarmos o modelo Biopsicossocial e Organizacional (BPSO-96) de QVT, o qual consiste justamente em valorizar positivamente o emprego 
de um conjunto sofisticado de motivos estímulos para a atividade de trabalho, por meio de ações e programas organizacionais baseados em indicadores difundidos como representantes de qualidade de vida no trabalho.

Isso é possível ser observado nos indicadores do modelo BPSO-96 de Limongi-França (1996) supracitados no Quadro 1. São exemplos, nesse sentido: na dimensão biológica: "Convênio médico", "Oportunidade de realizar ginástica durante $o$ trabalho", "Qualidade das refeições oferecidas pela empresa" etc.; na dimensão psicológica: "Gestão de clima organizacional de camaradagem", "Respeito à vida pessoal dos empregados", "Administração de salários satisfatórios", "Ferramentas de avaliação de desempenho", "Plano de carreira" etc.; na dimensão social: "Financiamento da educação", "Convênios comerciais", "Administração da previdência privada", "Fornecimento de cesta básica", "Atendimento aos filhos", "Oportunidades de atividade de lazer" etc.; na dimensão organizacional: "Oportunidades de treinamento e desenvolvimento", "Endomarketing", "Redução da burocracia", "Gestão participativa" etc.

Muitos indicadores desse modelo refletem benefícios que não são incorporados ao salário, mas que invadem a vida pessoal do trabalhador e fazem com que ele se vincule intensamente e se torne dependente da empresa. Os benefícios oferecidos revelam possibilidades de ações organizacionais que visam a criação de um sentimento de pertencimento e um maior envolvimento emocional no trabalho, ao fazer com que o trabalhador se sinta valorizado e ouvido em um ambiente familiar entre colegas. $\mathrm{Ou}$, na contramão, almejam motivar o trabalhador a estar mais produtivo, por meio do controle constante de sua produtividade, de forma que ele precise periodicamente provar que seu desempenho está adequado às demandas do sistema de trabalho imposto pela organização a fim de que não perca seu emprego. Nenhum deles, contudo, promove o envolvimento efetivo do trabalhador com o processo, o produto e o valor social de seu trabalho. O que ocorre é apenas o controle do pensamento, dos afetos (sentimentos e emoções) e do comportamento dos trabalhadores.

Todavia, uma vez que os motivos estímulos atuam por pouco tempo, de modo imediato, efêmero e sob circunstâncias diretas, após seu efeito resta ao trabalhador apenas o motivo principal de sua atividade de trabalho; o motivo que, na sociabilidade capitalista, lhe gera sentido: o salário, diretamente ligado à necessidade de sobrevivência do trabalhador. Embora o salário como motivo gere sentido para o trabalho, trata-se de um motivo e um sentido deslocados, alienados, do conteúdo, do produto e da finalidade social de sua atividade e que, portanto, não promove o desenvolvimento e o enriquecimento da personalidade do trabalhador.

Isso pode acarretar, a despeito do uso e abuso desses motivos estímulos, o enfraquecimento da motivação para a atividade de trabalho. E, com isso, ocorre prejuízo no desempenho e na produtividade do trabalhador, além de vivências de descontentamento e sofrimento. Daí a necessidade das estratégias de gestão do capital estarem frequentemente se reinventando, introduzindo novos e cada vez mais poderosos motivos estímulos para impulsionar o trabalho alienado - sejam eles positivos ou negativos, ou seja, motivos que gerem sinalizações psíquicas ou reações emocionais positivas (prazerosas) ou negativas (aversivas, ameaçadoras).

Psicologicamente, a grande quantidade, força e diversidade de motivos estímulos propostos pelo modelo de QVT em tela, para impulsionar a atividade do trabalhador, pode obscurecer sua consciência a respeito do motivo principal de seu trabalho: o pagamento que recebe pela venda da sua força de trabalho e que será trocado pelos bens que satisfazem suas necessidades biológicas, psicológicas e sociais. Ou seja, na hierarquia de motivos do trabalhador, aquele que de fato produz o sentido de seu trabalho acaba ficando camuflado 
diante da infinidade de motivos estímulos que lhe são colocados dentro do processo de trabalho. É nesse sentido que Leontiev (1978a) afirma que os motivos formadores de sentido, apesar de possuírem um lugar hierárquico superior e dominante na esfera motivacional da personalidade do indivíduo, podem permanecer "nos bastidores" de sua consciência.

Esse aspecto psicológico tem um papel gerencial e organizacional importante ao enfraquecer os efeitos negativos decorrentes do fato de o motivo e sentido do trabalho serem predominante externos a essa atividade; ou seja, do fato de o trabalho ser apenas um meio para o trabalhador e não um fim em si mesmo. Em outras palavras, atenua-se, ainda que temporária e parcialmente, a perda de interesse, a desmotivação, o sentimento de labuta e de se realizar um trabalho árduo e penoso, mascarando o sofrimento que dele pode advir. Com isso, reduz-se a provável queda de produtividade do trabalhador.

Leontiev (1978a) explica que, na atividade, os objetivos e as ações são sempre, de uma forma ou de outra, reconhecidos. Trata-se de uma questão diferente, porém, se o objeto é reconhecido como motivo. Isso porque a existência de motivos e a consciência deles são dois fenômenos distintos. Apesar de todas as atividades serem dotadas de motivos, é possível a ocorrência de atividades cujos motivos se encontram objetiva e subjetivamente ocultos para o indivíduo. Contudo, Martins (2001) enfatiza que os motivos não conscientes possuem a mesma determinação que qualquer outro, só podendo serem reconhecidos pelo sujeito por meio de sua relação com o mundo exterior. Assim, conforme Leontiev (1978a), os motivos são revelados para a consciência somente objetivamente a partir da análise da atividade e de sua dinâmica.

Mesmo quando os motivos não são reconhecidos, quando o homem não leva em conta para si mesmo o que fez com que ele realizasse determinada ação, ainda assim seu motivo possui reflexão psíquica. Porém, de uma forma especial, através da coloração emocional que se transfere para a ação.
A transferência da coloração emocional para a ação acontece em virtude da quebra da função dos motivos, que pode ocorrer ao longo do desenvolvimento da atividade humana. Esta quebra é consequência do fato de a atividade se tornar multifuncional, ou seja, responder simultaneamente a dois ou mais motivos que podem coexistir, apesar de em planos objetivos e subjetivos diferentes (LEONTIEV, 1978a).

A despeito do fato de os motivos estímulos introduzidos no trabalho com base no modelo BPSO96, ou em outro modelo qualquer de QVT, não gerarem sentido para essa atividade em si mesma, eles são sempre reconhecidos pelos sujeitos, uma vez que têm a função de impulsionar e estimular o desenvolvimento da atividade de trabalho como um todo ao ligar-se com os objetivos particulares das ações que lhe compõem. Já o motivo gerador de sentido, o motivo principal da atividade de trabalho, apesar de ocupar um lugar superior na hierarquia dos motivos e na esfera motivacional e emocional da personalidade do trabalhador, pode não estar consciente para ele no decorrer da execução de sua atividade.

Logo, o trabalhador executa suas ações sem se dar conta do motivo principal que conduz a sua atividade, sem estar consciente da ligação de suas ações com o motivo mais amplo de sua atividade. Apesar disso, este motivo se expressa psiquicamente por meio do tom emocional que é transferido às suas ações. Assim, embora o motivo gerador de sentido para o trabalho (o salário) possa não estar totalmente consciente para o trabalhador, em virtude dos variados motivos estímulos sobrepostos na hierarquia dos motivos desenvolvidos em sua atividade e que lhe sufocam, ele ainda encontra sua reflexão emocional em sua consciência.

Consequentemente, o trabalhador pode vivenciar em sua atividade situações emocionais de sofrimento, sem reconhecer as relações objetivas às quais esta vivência afetiva está atrelada. E, o que é ainda pior, identificando ou sendo identificado em si mesmo as causas do seu sofrimento e desajuste, 
negando o papel das condições objetivas e sociais nesse processo. Aprofunda-se e se intensifica, portanto, com a adoção dos modelos de QVT pela gestão organizacional, o fenômeno da alienação no trabalho.

\section{Conclusão}

Neste artigo nos propusemos a analisar criticamente o modelo BPSO-96 de QVT, a partir da teoria da atividade de Leontiev. Ao final, juntamo-nos, no entanto, aos críticos da QVT no questionamento acerca de qual seria a solução para o problema da qualidade de vida no trabalho nas organizações capitalistas.

Padilha (2009), assim como Araújo (2009), defende que, embora seja problemático acreditar que a oposição entre capital e trabalho será transformada em parceria por meio do desenvolvimento das políticas de QVT, ainda assim é melhor tê-las do que não realizar medida alguma. Tal posicionamento, ressalta Araújo (2009), não significa concordar com o perverso sistema de produção capitalista, muito menos com o rótulo de "humanização" que essas práticas adquiriram no discurso empresarial.

Concordarmos com ressalvas com a argumentação dos autores. Questionamo-nos se de fato é melhor do que nada implementar as práticas de QVT nas organizações. Isso porque, em nosso entendimento, essas práticas acirram os processos de alienação no trabalho. Oferecem certo conforto e alívio momentâneo, permitindo que o trabalho possa ser suportável para o trabalhador; provisoriamente, programas como este aliviam, mas não atacam as reais causas da situação que determina a própria necessidade de se pensar em e implementar programas de QVT. E justamente por anestesiar o trabalhador e contribuir para que a alienação e a exploração ao qual ele está submetido não se tornem conscientes, esses programas contribuem para distanciá-los ainda mais do ataque às reais causas estruturais do problema. Embora colaborem para dar um estímulo ao trabalhador, esse estímulo momentâneo distrai e pode afastá-lo do engajamento em mobilizações rumo à organização coletiva necessária para a superação das relações sociais de dominação, exploração e alienação.

Em nosso ponto de vista, a verdadeira Qualidade de Vida no Trabalho emergirá apenas a partir do momento em que as relações de dominação, exploração e alienação próprias do modo de produção capitalista forem superadas. Os programas de QVT nas organizações, como estratégia patronal disfarçada de humanismo e paternalismo, servem apenas como medida paliativa, assistencial, superficial e de controle para os problemas relacionados à motivação, ao desempenho $\mathrm{e}$ à produtividade do trabalhador. Mascaram o verdadeiro sentido do trabalho no capitalismo e seu caráter alienado, aprofundando ainda mais os processos de alienação no trabalho e "docilizando" o trabalhador na contramão do movimento coletivo necessário à sua real emancipação. Portanto, seu real papel deve lhe ser revelado, denunciado.

\section{Referências}

ARAÚJO, J. N. G. D. Qualidade de vida no trabalho: controle e escondimento do mal-estar do trabalhador. Trabalho Educação e Saúde, Rio de Janeiro, v. 7, n. 3, p. 573-585, nov. 2009/fev. 2010.

BOM SUCESSO, E. D. P. Trabalho e qualidade de vida. Rio de Janeiro: Qualitymark, 1998.

CAMPANA, D. P. Desenvolvimento e avaliação de projeto em qualidade de vida no trabalho (QVT): indicadores de produtividade e saúde nas organizações. Dissertação (Mestrado em Engenharia de Produção) Universidade de São Paulo, São Carlos, 2011.

CARVALHO, C. A.; DOURADO, D. C. P. Extra! Extra! O caso do Metrorec revela como é operada a manipulação ideológico do discurso da QVT. Cadernos EBAPE.BR, Rio de Janeiro, v. 5, n. 4, dez. 2007.

CHIAVENATO, I. Gestão de pessoas: o novo papel dos recursos humanos nas organizações. 3. ed. Rio de Janeiro: Elsevier, 2010.

DUARTE, N. A Individualidade para si: contribuições a uma teoria histórico-social da formação do indivíduo. São Paulo: Autores Associados, 2008. 
DUARTE, N. A teoria da atividade como uma abordagem para a pesquisa em educação. Perspectiva, Florianópolis, v. 20, n. 2, p. 279-301, jul./dez. 2002.

DUARTE, N. Formação do indivíduo, consciência e alienação: o ser humano na psicologia de A. N. Leontiev. Cadernos CEDES, Campinas, v. 24, n. 62, p. 44-63, abr. 2004.

FERNANDES, E. C. Qualidade de vida no trabalho: como medir para melhorar. 2. ed. Salvador, BA: Casa da Qualidade, 1996.

FERREIRA, M. C. Qualidade de vida no trabalho: do assistencialismo à promoção efetiva. Laboreal, Porto, PT, v. 11, n. 2, p. 28-35, 2015.

FERREIRA, M. C.; ALVES, L.; TOSTES, N. Gestão de qualidade de vida no trabalho (QVT) no serviço público federal: o descompasso entre problemas e práticas gerenciais. Psicologia: Teoria e Prática, São Paulo, v. 25, n. 3, p. 319-327, jul./set. 2009.

LEONTIEV, A. N. Actividad, conciencia y personalidad. Buenos Aires: Ciencias del Hombre, 1978a.

LEONTIEV, A. N. O desenvolvimento do psiquismo. Lisboa: Livros Horizonte, 1978 b.

LIMONGI FRANÇA, A. C. Indicadores empresariais de qualidade de vida no trabalho: esforço empresarial e satisfação dos empregados no ambiente de manufaturas com certificação ISO 9000. Tese (Doutorado em Administração) - Universidade de São Paulo, São Paulo, 1996.
LIMONGI-FRANÇA, A. C. Qualidade de vida no trabalho: conceitos e práticas nas empresas da sociedade pós-industrial. São Paulo: Atlas, 2003.

LIMONGI-FRANÇA, A. C.; ARELLANO, E. B. Qualidade de vida no trabalho. In: FLEURY, Maria Tereza Leme (Org.). As pessoas na organização. São Paulo: Gente, 2002. p. 295-306.

LIMONGI-FRANÇA, A. C.; RODRIGUES, A. L. Stress e trabalho: guia básico com abordagem psicossomática. São Paulo: Atlas, 1996.

MARTINS, L. M. Análise sócio-histórica do processo de personalização de professores. 2001. Tese (Doutorado em Educação) - Faculdade de Filosofia e Ciências, UNESP, Marília.

PADILHA, V. Qualidade de vida no trabalho num cenário de precarização: a panaceia delirante. Trabalho Educação e Saúde, Rio de Janeiro, v. 7, n. 3, p. 549-563, nov. 2009/fev. 2010.

RODRIGUES, M. V. Qualidade de vida no trabalho: evolução e análise no nível gerencial. 11. ed. Petrópolis, RJ: Vozes, 2008.

SCOPINHO, R. A. Qualidade de vida versus condições de vida: um binômio dissociado. Trabalho Educação $e$ Saúde, Rio de Janeiro, v. 7, n. 3, p. 599-607, nov. 2009/ fev. 2010.

TOLFO, S. D. R.; PICCININI, V. C. As Melhores empresas para trabalhar no brasil e a qualidade de vida no trabalho: disjunções entre a teoria e a prática. $R A C$ : Revista de Administração Contemporânea, São Paulo, v. 5, n. 1, p. 165-193, 2001. 
